\title{
Effect Of Heat Transfer Enhancement: In Inner Tube With Apparatus
}

\author{
Ismet Faruk Yaka, Canan Gungor, Afsin Gungor
}

\begin{abstract}
In recent century due to technological advances and population have increased energy demand. Energy save and energy use efficiency has become important topic. Energy production, transmission process is related to heat transfer. When the heat transfer is enhancing at energy process, energy efficiency will increase. The heat transfer enhancement techniques are widely used in many applications in the heating process. These techniques are classified as active and passive techniques. The objective of this study is to increase heat transfer efficiencies in tube with passive techniques. For this purpose, various apparatus will place into inner tubes which increase the heat transfer surfaces. The experiments were performed with 3 different type apparatus. It was compare and analyzed efficiency of apparatus types.
\end{abstract}

\section{Keywords-Heat Transfer, Heat Exchanger, Energy Efficiency}

\section{Introduction}

Energy has become the most important cases in the last century. Energy production, consumption and transmission have become very important. Thermal energy is one of the important sources of energy. Scientists have a lot of study to be thermal energy production and transport.

The heat exchangers used to transfer thermal energy from one point to a point. Increasing performance of the heat exchanger, the energy can be used more effectively. In order to improve heat transfer and to increase thermal performance of the heat exchangers heat transfer enhancement techniques are extensively used. These techniques are categorized in two groups, active and passive techniques.

Ismet Faruk YAKA

Akdeniz University

Turkey

Canan GUNGOR

Akdeniz University

Turkey

Afsin GUNGOR

Akdeniz University

Turkey
For active techniques heat transfer ratio is improved by providing extra energy to the system while in passive techniques the purpose is solved without use of any extra energy. The passive techniques include surface area extension (extended surfaces: fins), rough surfaces, inserts, turbulators also called swirl flow devices and coated surfaces.

The literature review in this area shows that a lot of research work has been carried out on passive techniques, specially wire coil inserts and twisted tapes. Bodius Salam et al. [1] experimentally investigated turbulent flow in a circular tube fitted with rectangular-cut twisted tape insert, for measuring heat transfer enhancement efficiency of water, friction factor and tube-side heat transfer coefficient.

Concentric and double tube in horizontal tube of the inner annular member located within the wire effect on heat transfer and pressure drop, it has been investigated by Naphon [2]. Sewall et al [3], placing the tube into a fixed internal elements flow and heat transfer characteristics were determined experimentally. Kamali and Binesh [4] examined the heat transfer occurring in a square cross section of the inner member is placed in pairs have different geometry and friction channel numerically.

Laminar and unsteady at a flow, a tube is placed into three different pitch rate of the wire loop heat transfer effect on healing have been examined by Garcia et al. [5]. For Reynolds numbers between 200 and 1000, wire coils remarkably increase heat transfer. At Reynolds number around 1000, has increased the heat transfer up to eight times.

Ozceyhan [6], the four different rings in the flow in a pipe group (S1, S2, S3, S4) studied experimentally using heat transfer to improve the Reynolds number in the range from 3940 to 50125. Maximum heat transfer increase was obtained from the ring group S1 for both the same Reynolds number. The ring group (Sl) was provided approximately $34 \%$ and 20 $\%$ heat transfer enhancement at high and low Reynolds numbers, respectively.

From this point of view, in this study, the effect of increasing the heat transfer by adding 3 different turbulators, 
twisted tape, straight wire and ceramic ball, to the pipe was investigated.

\section{Methods}

In this study, the change of heat transfer was investigated by using 3 different apparatus in pipe. The schematic diagram of the experimental set up is shown in Fig 1.

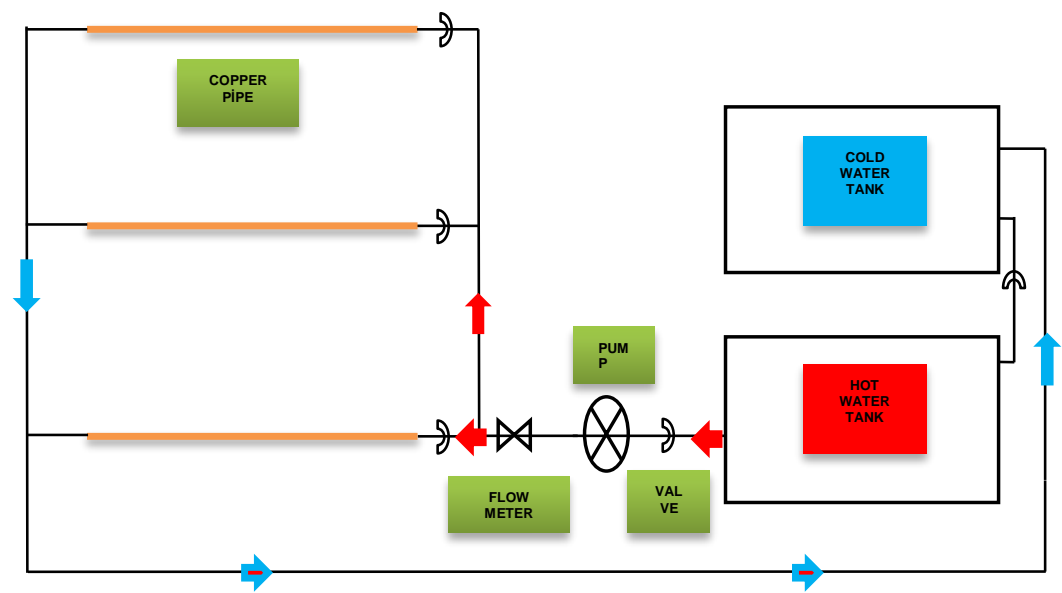

Figure 1. Schematic Diagram of the Experimental Setup

Experimental setup test section was made from $3000 \mathrm{~mm}$ of copper tube outer diameter 7,94 $\mathrm{mm}$ and inner diameter $0,70 \mathrm{~mm}$. Experimental set up has 3 copper tube.

Experimental setup except for copper tube has a pump, a flow meter, cold water tank, hot water tank, valve and heater for heating water. Cold water and hot water tank capacities are 150 liter. Heater heating capacity is 2000 watt.

The general view of the pump used in the experimental setup is given in Figure 2. The characteristics of the pump:

- $0,37 \mathrm{Kw}$ Power

- $\quad 38$ 1/min Capacity

- $40 \mathrm{~m}$ maximum head

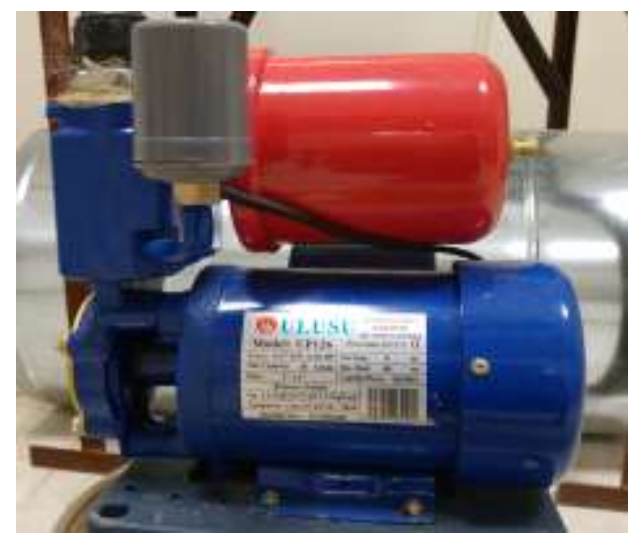

Figure 2. Circulation Pump

Testo 176T4 datalogger and $\mathrm{k}$ type thermocouple are used for temperature measurements. The general view of the data logger used in the experimental setup is given in Figure 3.

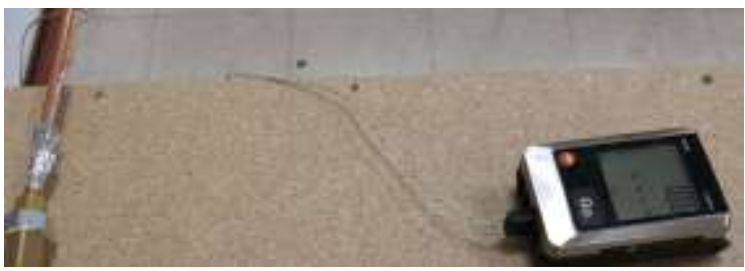

Figure 3. Temperature data logger

Figure 4 shows the twisted tape. A stainless steel twisted tape was made by twisting $1 \mathrm{~mm}$ thick (t) $20 \mathrm{~mm}$ width (w) straight strip. Tape pitch (y) of $80 \mathrm{~mm}$ was made which gave twist ratio $(\mathrm{y} / \mathrm{w}) 4$.

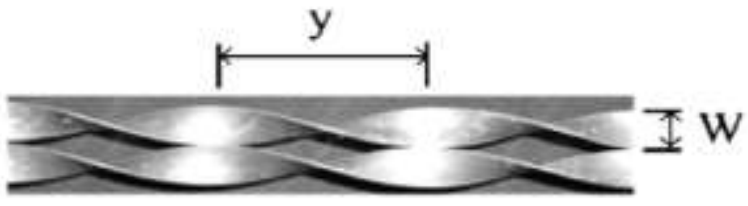

Figure 4. Twisted Tape

Figure 5 shows the straight wire. Straight wire is steel and it is $3 \mathrm{~mm}$ diameter.

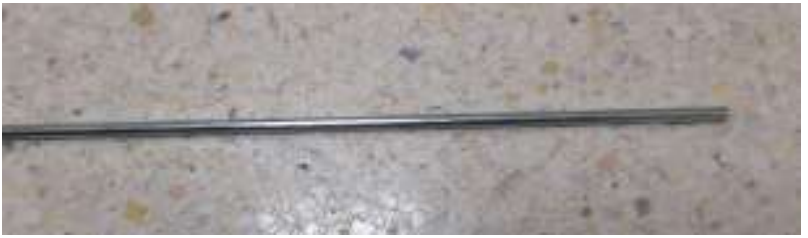

Figure 5. Straight wire steel 
Figure 6 shows the ceramic ball. The ceramic ball diameter is $5 \mathrm{~mm}$.

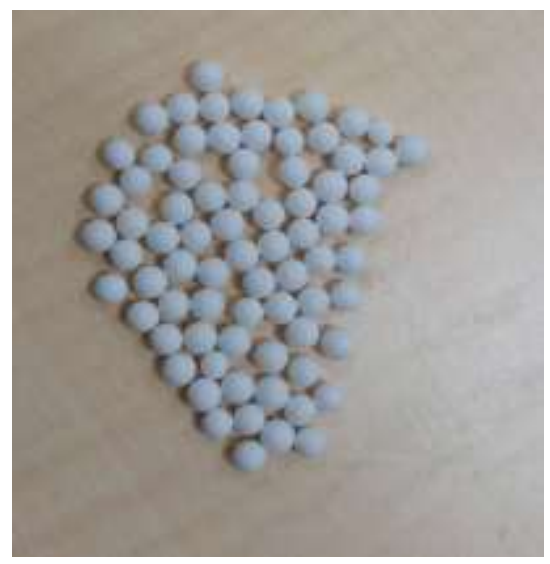

Figure 6. Ceramic Ball

First the heater is started and heating water. After, the temperature at the outlet of the hot water tank is measured. When the temperature is to attained 95 degrees Celsius, the pump is started. Then the valves open and the water circulate. 10 minutes are waiting for until the system reaches the regime. When the system reached regime, measurement is start. Temperature measurement is made on copper pipe from 4 different points.

\section{Results and Discussion}

Experiments were carried out with blank tube, twisted tape, straight wire and ball turbulator in accordance different reynolds numbers. The variation of the Reynolds number with the Nusselt number according to the experimental results is given in figure 7.

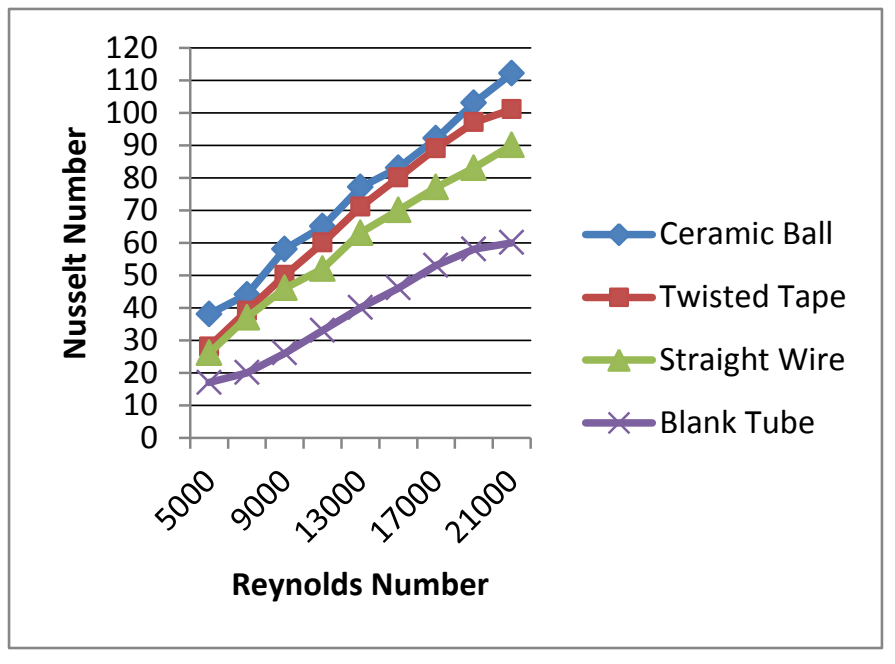

Figure 7. The variation of Nusselt number with Reynolds number
When examined Figure 7, the number of Reynolds changes from 5000 to 21000 is seen. Because the Reynolds number is bigger than 2300 the flow is turbulent. The number of Nusselt changes from 18 to 115 . Nusselt numbers increased with the increase of Reynolds number.

When the Nusselt number is increased also heat transfer increased. From here, if the Nusselt values of the turbulators placed in the pipe are checked:

The number of Nusselt of ceramic ball turbulators varies between 38 and 113. Because it has the highest nusselt number, the ceramic ball turbulator has the highest heat transfer. It reveals the importance of ceramic ball turbulators in terms of increasing heat transfer.

The number of Nusselt of twisted tape turbulators varies between 29 and 102. Because it has the second highest Nusselt number, the twisted tape turbulator has the second highest heat transfer. The twisted tape turbulator has less heat transfer compared to the ceramic ball turbulator.

The number of Nusselt of straight wire turbulator varies between 26 and 90 . Because it has the less Nusselt number compared other turbulators, the twisted tape turbulator has the low heat transfer.

The heat transfer in the blank tube was realized as the lowest heat transfer. The number of Nusselt of blank tube varies between 18 and 60. It has the lowest Nusselt number. Therefore, the lowest heat transfer is also achieved in the blank tube.

In the range of 5000-7000 Reynolds numbers, the change in Nusselt number between blank tube and straight wire turbulator showed a rapid increase. After that point the difference has increased too much. In summary, a turbulator placed inside the tube has seriously increased heat transfer compared to the blank tube. From this point, the heat transfer in tube was maximum with the ball turbulator and the ball turbulator was determined as the ideal.

\section{Conclusion}

In this study, an experimental investigation was carried out for measuring heat transfer enhancement efficiency of water for turbulent flow in tube. For this purpose 3 different turbulators, twisted tape, straight wire and ceramic ball were used in a copper tube. When ceramic balls were added into the copper pipe, the Nusselt number increased twice in the range of 5000-21000 reynolds compared to the empty pipe, and the heat transfer reached the maximum level. In the other two 
turbulators, the number of nusselts increased about 1.5 times. As a result, it has been found beneficial in terms of increasing heat transfer through the use of ceramic balls in the in-pipe flow.

\section{References}

[1] Salam. B., Biswas. S., Saha. S., and Bhuiya, M. M. K, "Heat transfer enhancement in a tube using rectangular-cut twisted tape insert," Procedia Engineering, vol. 56, pp. 96-103, 2013

[2] Naphon. P, "Effect of Coil-Wire Insert on Heat Transfer Enhancement and Pressure Drop of the Horizontal Concentric Tubes," International Communications in of Heat and Mass Transfer, vol. 33, pp. 753-763, 2006.

[3] Sewall. E. A., Tafti. D. K., Graham. A. B., and Thole. K. A., "Experimental validation of large eddy simulations of flow and heat transfer in a stationary ribbed duct," International journal of heat and fluid flow, vol. 27(2), pp. 243-258, 2006.

[4] Kamali. R, and Binesh. A.R, "The Importance of Rib Shape Effects on the Local Heat Transfer and Flow Friction Characteristics of Square Ducts with Ribbed Internal Surfaces," International Communications in Heat and Mass Transfer, vol. 35(8), pp. 1032-1040, 2008.

[5] Garcia. A., Solano. J. P., Vicente. P. G., and Viedma. A, "Enhancement of laminar and transitional flow heat transfer in tubes by means of wire coil inserts," International Journal of Heat and Mass Transfer, vol. 50(15), pp. 3176-3189, 2007.

[6] Ozceyhan, V., "Experimental Investigation of Flow and Heat Transfer in a Rib Inserted Pipe," Ph.D. Thesis, Erciyes University, December 2002. 